\title{
LOCATOR VERSUS STRESS FREE IMPLANT BAR ATTACHMENTS FOR TWO -IMPLANTS IMMEDIATELY LOADED BY MANDIBULAR OVERDENTURES. A ONE YEAR RANDOMIZED STUDY
}

\author{
Samer Mostafa Ali * and Dina Bahgat El Talawy **
}

\begin{abstract}
Aim: The purpose of this short-term randomized trial was to study clinical and radiographic outcomes of Locators and stress free implant SFI bar attachments used for two -implants immediately loaded by mandibular overdentures.
\end{abstract}

Material and method: Twelve edentulous participants ( 6 males and 6 females) received new maxillary and mandibular dentures and wore them for 3 months to increase muscular control. Two fixtures were installed in the canine regions of the mandible and immediately loaded by mandibular overdentures using Locator (group 1) or SFI bar (group 2) attachments. Plaque index (PI), gingival index (GI), probing depth (PD), stability of the implants (IS), and marginal bone resorption (BL) were measured at base line (insertion), 6 and 12 months later.

Results: The implant survival was $91.7 \%$ and $100 \%$ for Locator and SFI bar groups respectively. PI, PD and BL increased significantly with time in both groups. SFI bar group showed significant higher PI and PD than Locator group after 6 and 12 months. On the other hand, Locator group showed significant higher BL than bar group at 6 and 12 months. No significant difference in GI and IS between observation times or between groups was noted.

Conclusion: Within limitation of this study, it is concluded that both Locators and SFI bar anchors are recommended for immediately loaded 2 inter-foraminal implants by mandibular overdentures. However, Locators may be favorable regarding improved peri-implant soft tissue conditions and SFI bar may be favorable regarding reduced marginal bone loss around the implants.

\section{INTRODUCTION}

Overdentures in the mandible retained by two implants placed in the interforaminal region have been well documented in clinical investigations and have been suggested as standard treatment for the edentulous patient ${ }^{1}$. The implant-retained overdenture provides functional stability and retention, and improved food soft and hard

\footnotetext{
* Associate Professor, Removable Prosthodontics Department, Faculty of Dentistry, October University for Modern Science and Arts (MSA), Egypt.

** Associate Professor, Removable Prosthodontics Department, College of Oral and Dental Surgery, Misr University for Science and Technology, Egypt.
} 
food chewing, enhanced phonation, improved appearance, and better stomatognathic functions than complete dentures ${ }^{2}$. Several connectors may be used with overdentures including splinted ones such as bars or individual attachments such as locators, balls, and magnets ${ }^{1}$. The use of one-stage surgical procedures and immediate loading protocols is one way to simplify implant treatment, short healing time, minimize postoperative discomfort ${ }^{3}$, and to provide immediate restoration of mastication and esthetics ${ }^{4}$. It is possible that non-splinted implants may be negatively affected by immediate loading because the load is not shared between implants ${ }^{5}$, i.e. decreased stability and/or marginal bone resorption ${ }^{6}$. For immediate loading protocol, the effect of attachment on the forces transmitted to bone around implants is a critical factor than for conventionally loaded implants ${ }^{7}$.

The Locator attachment has double retention comes from outer and inner flanges and it has different retention forces with different colors of nylon inserts ${ }^{8,9}$. Locator is resilient, and includes a nylon inserts that can be used to remove problems of angulated implants up to $30^{0} 10-12$. With limited interarch space, locators are used to minimize bulk of the prosthesis ${ }^{13}$, avoid increase in vertical dimension, and patient dissatisfaction. ${ }^{14}$. Locator attachments have a low height and can be used with limited inter arch space to avoid denture base deformation and fracture $^{13,15}$. In the last decade, stress free-implant bar (SFI bar, Cendres+Metaux SA) was introduced as a ready-made precise round bar that allow chairside adaption for immediate loading protocol ${ }^{16}$. This bar connects implants with no soldering or laserwelding. This allows construction of a passive-fit bar $^{17}$ with reduced corrosion ${ }^{18}$. Moreover, this bar can be used with individual implant angulations up to $15^{\circ 19}$. The bar consists of 2 or 4 ball joints that are connected to implant adapters by screws and tube bar. It can be adjusted to variable interimplant distance. The bar is supplied with 2 types of female part, the E-clips (Elitor precious metal alloy) and the
T-clips (all titanium grade IV with nylon inserts) ${ }^{17}$. Despite these several advantages, the success of SFI bar needs to be investigated in clinical studies ${ }^{19}$. Reviewing the literature, space requirement of a prefabricated SFI bar on two implants retaining mandibular overdentures was investigated ${ }^{20}$. However, the clinical performance of SFI for immediately loaded 2 implants assisting mandibular overdenture was not evaluated. Therefore, this study aimed to investigate clinical and radiographic peri-implant tissue responses of Locator and stressfree implant bar (SFI bar) attachments for two -implants immediately loaded by overdentures after 12 months. The authors hypothesis was that no significant difference in the tested outcomes between the 2 attachments.

\section{MATERIALS AND METHODS}

Twelve edentulous patients (6 males and 6 females) who were unsatisfied with retention and stability of their mandibular dentures were selected from this study from the patients attending regularly at the clinic of the prosthodontic department of College of Oral and Dental Surgery of Misr University for Science and Technology. The inclusion criteria are:

1. Sufficient residual bone volume in the intraforaminal area to receive two $3.5 \times 11 \mathrm{~mm}$ implants with sufficient bone quality. Bone quantity and quality and implant position and angulation were verified by preoperative cone beam CT.

2. No history of previous implant surgery.

3. Absence of local inflammation and oral mucosal diseases.

4. Sufficient inter-arch space.

\section{The exclusion criteria were:}

1. History of radiotherapy in the head and neck region. 
2. Metabolic diseases such as diabetes mellitus.

3. Liver and heart diseases and blood disorder.

4. A history of preprosthetic surgery.

5. Severe maxillomandibular skeletal discrepancy.

6. Excessive parafunctional activity.

7. Smoking habit and uncooperative patients.

Patients were randomly classified into 2 groups using random numbers generated in excel sheet (Microsoft office) with equal gender distribution in each group: Group I (G1); included 4 patients who received Locator retained mandibular overdentures, and group II (G2); included 4 patients who received SFI bar retained mandibular overdentures. All patients informed about treatment protocol and merits and all of them signed an informed consent. The Local ethical committee of the faculty approved the study protocol (ETH 30).

\section{Surgical and prosthetic procedures}

Conventional upper and lower dentures were made using standard procedures ${ }^{21}$. Semi-anatomic acrylic resin teeth (Acrostone-Egypt) were arranged in bilateral balanced occlusion. The patients wear the dentures for 3 months to increase neuro muscular adaptation and necessary adjustments were made. A radiographic stent and cone beam $\mathrm{CT}$ (CBCT, i-CAT Vision ${ }^{\circledR}$, USA) was made. Duplicate lower denture was used as a radiographic stent. Gutta purcha were fixed to polished surface of the denture ${ }^{22}$. A tissue supported surgical guide was constructed by prototyping technology using 3D imagebased software (OnDemand3DApp Software; CyberMed Inc). A surgical kit including sleeves and standardized drills (supplied by the radiologist) was used for osteotomy preparation. The guide was fixed in the mandibular bone using anchor pins. For both groups, 2 implants (Neoss Ltd., Harrogate, England) were inserted inter-foraminally in the canine region using one-stage non-submerged flapless protocol. The osteotomy sites were prepared following the drilling sequence provided by the manufacturer's surgical universal kit. During the implant insertion, a minimum $35 \mathrm{Ncm}$ value of insertion torque was achieved ${ }^{23}$. Immediately after implant insertion, Locator abutments (group 1) and SFI bar abutments (adapters) (group 2) were threaded to the implants with a $30 \mathrm{~N} / \mathrm{cm}$ torque. For group 1 (Locators) sufficient relieve was provided in the mandibular dentures over abutments to provide a space for the attachment. The Locator metal housings were attached to the abutments. A circular small pieces of rubber dam and white blocking rings were snapped on the locator abutments to prevent flow of the acrylic resin in the undercuts of the abutments. The metal housings with processing inserts were attached to the lower denture using self-cure acrylic resin while the participants close in retruded contact position (fig 1). After finishing and polishing, the processing inserts were replaced by blue nylon insert (extra light retention). Excess acrylic resin around the abutments was removed to avoid unnecessary loading of the implants and the denture was finished and polished. For group 2 (SFI bar), the implant adapters (bar abutments) of the SFI-Bar ${ }^{\circledR}$ (Cendres + Metaux, Biel/Bienne, Switzerland) were screwed to the implants and tube bars were screwed to the implant adapter by using screw driver. The ball joint on one side was fixed with screws. The tube bar and tube bar gauge on the other side was slide onto the pin of the ball joint until the gauge could be fitted onto the other implant adapter and screwed. The tube bar was sectioned with disc. The shortened tube bar was slide onto the pin and retightened tension-free. Two plastic clips (red, light retention) were inserted in the metal housings and fastened to the bar intraorally. Sufficient relieve in the fitting surface of mandibular dentures was made using disclosing media till no contact was present between the denture and the sleeves of the bars. The space under and around the bars was blocked out with wax. The metal housings and retentive clips were picked up intraorally to ensure passive fit (fig2). The overdentures were 
delivered to the patients immediately after implant placement, and soft diet and 2-weeks regular recall visits for adjustments were scheduled all over the study period. Hygiene instructions were given to patients. All patients administered antibiotics (1 $\mathrm{g}$ of amoxicillin and clavulanic acid/ 2 times per day) and Anti-inflammatory drugs (Cataflam 50 $\mathrm{mg} / 3$ times per day) and mouth rinse with a $0.12 \%$ chlorhexidine digluconate (for 7 days).

\section{Implant related outcomes}

\section{A) Clinical outcomes}

The following parameters were recorded for each implant by the same examiner at time of overdenture insertion, 6 and 12 months later:
- Plaque index (PI) according to Mombelli et al. ${ }^{24}$ and Gingival index (GI) according to Loe and silness ${ }^{25}$ were measured.

- Probing depth (PD): measured between gingival border and the base of the pocket using a periodontal probe and recorded as probing depth.

PI, GI and PD recorded at mid-mesial, midlabial, mid-distal and mid lingual aspects of each implant.

- Implant stability (IS): was measured by means of resonance frequency analysis (RFA, Osstell ${ }^{\mathrm{TM}}$ ) and expressed with ISQ measurement scale (implant stability quotient) after attaching the implant-specific SmartPegs to the implant ${ }^{26,27}$.

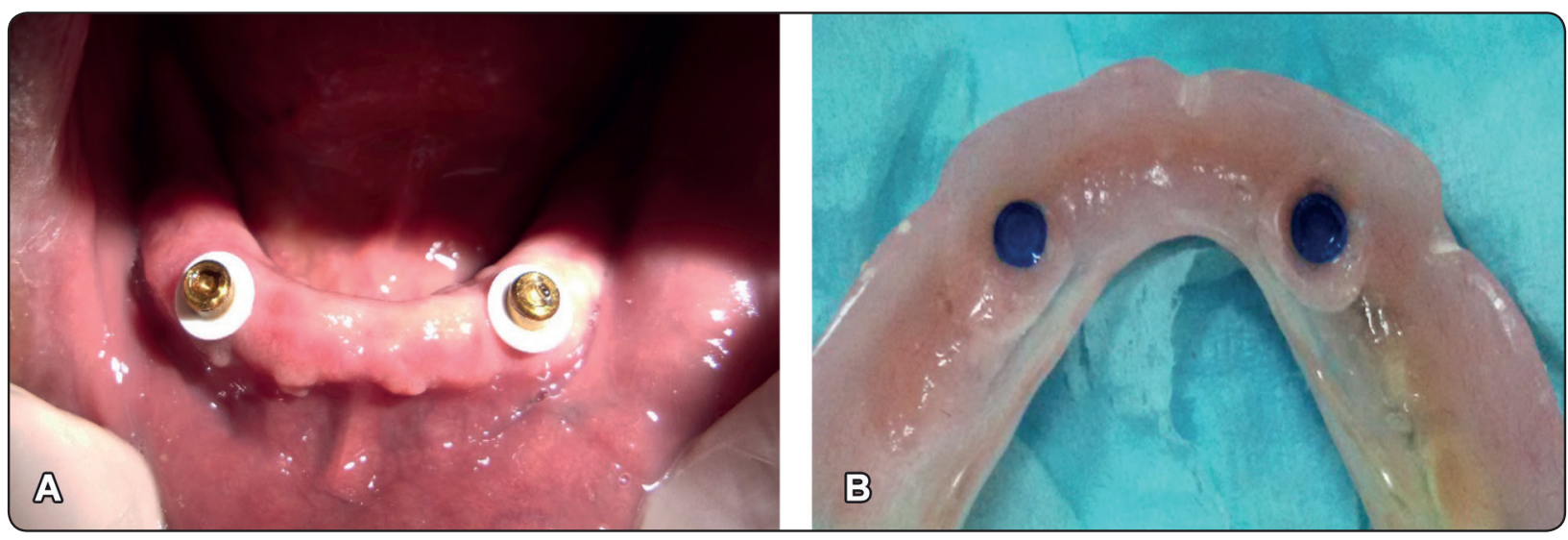

Fig. (1) Locator overdentures (group 1), A; locator abutments in patient mouth, B; Fitting surface with attachments

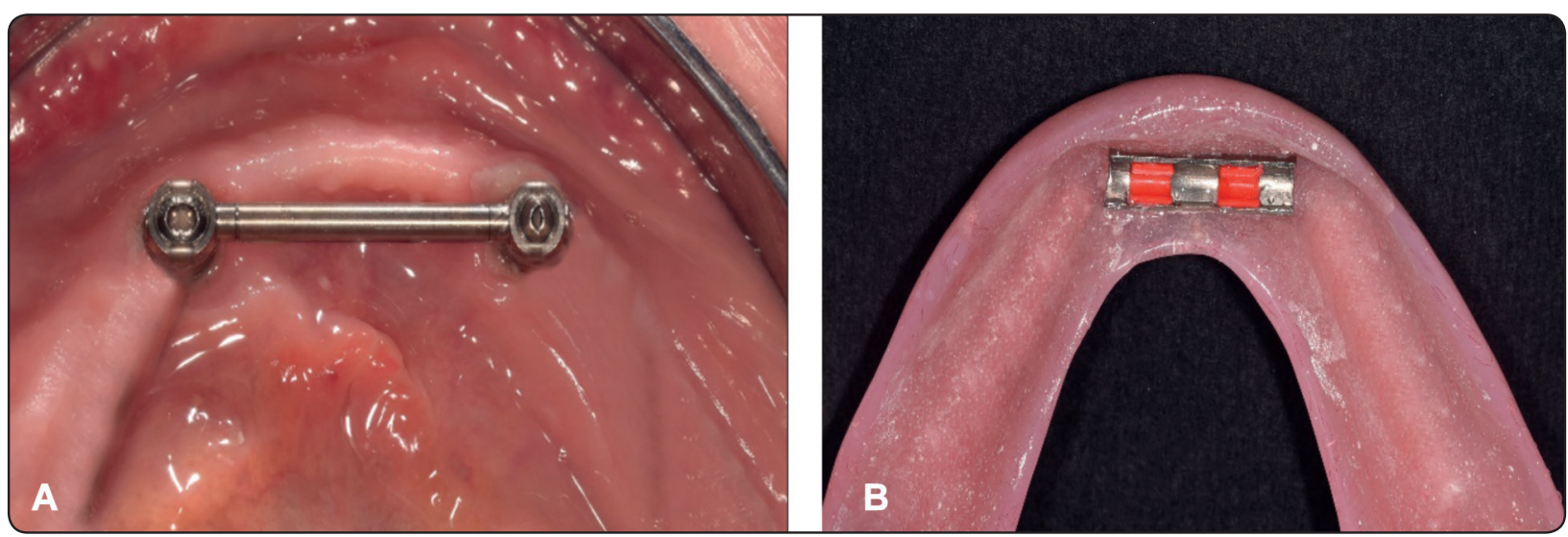

Fig. (2) SFI bar overdentures (group 2), A; SFI bar in patient mouth after adjustement , B; plastic red clips 


\section{B) Radiographic outcome}

Marginal Bone loss (MBL): bone height was detected using periapical radiographs and Rinn XCP film holder (Dentsply). For standardization of film position, rubber base bite blocks were attached to the film holder and the patient bite on them in centric occlusion. This bite block was used during subsequent film exposures in the follow up visits. The implant platform was used as the reference point (point A) (Fig 3). Evaluation of the marginal bone level around implants was performed using image analysis software (Digora Optime, Orion Corp./ Soredex). The known implant dimensions were used to compensate for radiographic magnification ${ }^{28}$. The distance between the reference point and boneimplant connection indicated bone level. Marginal bone loss (BL) was determined by subtracting bone level after 6 and 12 months from values at base line. Measurements were made on both the mesial and distal aspects. All radiographic measurements were made by one calibrated examiner. Clinical and radiographic outcomes were measured at insertion, 6 and 12 months later.

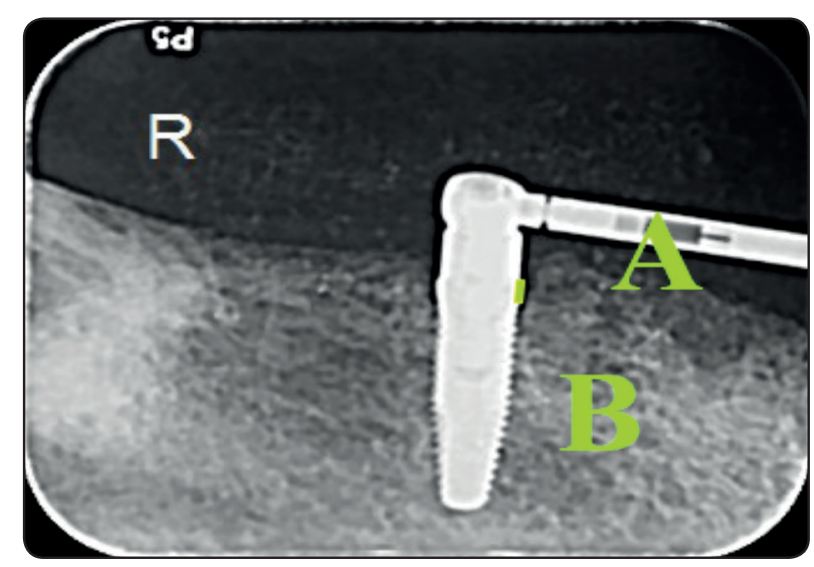

Fig. (3) Evaluation of marginal bone loss on digital periapical images

\section{Statistical analysis}

Shapiro-wilk Test was used to detect normality. Between-group comparisons for BL, PD, and IS were performed using student t-test, and for PI, GI using Mann-Whitney $U$ test. Repeated measure
ANOVA followed by LSD was used to detect significant differences between observation times for BL, PD, and IS. The Friedman and Wilcoxon's tests were to compare observation times for PI, GI. $\mathrm{P}<0.05$ is the level of significance. All statistical analyses were performed using SPSS $®$ software version 25 (SPSS Inc., Chicago, IL, USA).

\section{RESULTS}

One implant failed to integrate in the Locator group resulting $91.7 \%$ survival rate. Since the study was conducted according to intention to treat principle, the patient was excluded from further analysis. No implants were lost in SFI group and the survival rate was $100 \%$. Comparison of periimplant clinical parameters between Locator and SFI groups is presented in table 1. Plaque showed significant increase in both groups with passage of time. Multiple comparison between observation times is presented in table 3. Plaque scores differs significantly between each 2-time intervals except between baseline and 6 months in the Locator group. SFI bar group showed significant higher plaque scores than Locator group after 6 and 12 months. However, at base line no difference in plaque scores between attachments was noted. There was no significant difference in gingival index between time intervals and or between groups at each time interval.

Probing depth showed significant increase in both groups with passage of time. Multiple comparison between observation times is presented in table 3 . There was a significant difference in pocket depth between each 2-time intervals except between baseline and 6 months in the Locator group. SFI bar group showed significant higher pocket depth than Locator group after 6 and 12 months. However, at base line no difference in pocket depth between attachments was noted. There was no significant difference in implant stability between time intervals and or between groups at each time interval. 
Comparison of peri-implant marginal bone loss between Locator and SFI groups is presented in table 2. For locator group, BL after 6 months was $.81 \pm .11 \mathrm{~mm}$ and after 12 months was $93 \pm .20 \mathrm{~mm}$. For SFI group, BL after 6 months was $57 \pm .09 \mathrm{~mm}$ and after 12 months was $77 \pm .23 \mathrm{~mm}$.

Bone loss increased with significant difference from six months to 12 months for both groups. Locator group showed significant higher BL than bar group after 6 and 12 months.

TABLE (1) Comparison of peri-implant clinical parameters between Locator and SFI groups

\begin{tabular}{|c|c|c|c|c|}
\hline & $\begin{array}{c}\text { At insertion (base } \\
\text { line) }\end{array}$ & After 6 months & After 12 months & \\
\hline \multicolumn{4}{|c|}{ Plaque (PI) } & $\begin{array}{l}\text { Freidman test } \\
\quad(p \text { value })\end{array}$ \\
\hline Locator M (min-max) & $.5(.00-1.0)$ & $.6(.00-1.0)$ & $1.5(1.0-2.0)$ & $.045^{*}$ \\
\hline SFI bar M (min-max) & $.5(.00-1.0)$ & $1.24(1.0-2.0)$ & $2.1(1.0-3.0)$ & $.006^{*}$ \\
\hline Mann-Whitney test (p value) & 1.00 & $.035^{*}$ & $.025 *$ & \\
\hline \multicolumn{4}{|c|}{ Gingiva (GI) } & $\begin{array}{l}\text { Freidman test } \\
\text { (p value) }\end{array}$ \\
\hline Locator $\quad M(\min -\max )$ & $.5(.00-1.0)$ & $.4(.00-1.0)$ & $9.0(.00-1.5)$ & .16 \\
\hline SFI bar M (min-max) & $.5(.00-1.0)$ & $.6(0.0-1.2)$ & $1.0(5.0-1.5)$ & .25 \\
\hline Mann-Whitney test (p value) & 1.00 & .055 & .78 & \\
\hline \multicolumn{4}{|c|}{ Probing (PD) } & $\begin{array}{c}\text { Repeated measures } \\
\text { ANOVA }\end{array}$ \\
\hline Locator $\mathrm{X} \pm \mathrm{SD}$ & $0.50 \pm 0.2$ & $8.0 \pm 0.3$ & $1.5 \pm 0.4$ & $.046 *$ \\
\hline SFI bar $\mathrm{X} \pm \mathrm{SD}$ & $0.51 \pm 0.15$ & $1.5 \pm 0.43$ & $2.2 \pm 0.54$ & $.017 *$ \\
\hline t- test (p value) & 1.00 & $.025 *$ & $.018 *$ & \\
\hline \multicolumn{4}{|c|}{ Stability (IS) } & $\begin{array}{c}\text { Repeated measures } \\
\text { ANOVA }\end{array}$ \\
\hline Locator $\mathrm{X} \pm \mathrm{SD}$ & $65.33 \pm 2.01$ & $64.68 \pm 1.64$ & $65.40 \pm 1.42$ & .61 \\
\hline SFI bar $\mathrm{X} \pm \mathrm{SD}$ & $65.14 \pm 1.75 \mathrm{a}$ & $64.07 \pm 1.29 \mathrm{a}$ & $63.09 \pm 1.48 \mathrm{a}$ & .098 \\
\hline t- test (p value) & .66 & .32 & .084 & \\
\hline
\end{tabular}

M: median, min: minimum, max: maximum, $X$; mean, SD, standard deviation, *: p value significant at .05

TABLE (2) Comparison of peri-implant marginal bone loss between Locator and SFI groups

\begin{tabular}{|l|c|c|c|c|}
\hline \multicolumn{3}{|c|}{ Bone loss (BL) } & Repeated measures ANOVA \\
\hline Locator $\mathbf{X} \pm$ SD & - & $.81 \pm .11$ & $.93 \pm .20$ & $.012^{*}$ \\
\hline SFI bar $\mathbf{X} \pm$ SD & - & $.57 \pm .09$ & $.77 \pm .23$ & $.024 *$ \\
\hline t- test (p value) & - & $.033^{*}$ & $.048^{*}$ & \\
\hline
\end{tabular}

$X$; mean, SD, standard deviation, *: p value significant at .05 
TABLE (3) Multiple comparison between time intervals. Number in each cell indicating $\mathrm{p}$ value of Wilcoxon sign ranks test (PI and GI) and paired t-test (PD, IS, and BL) between each 2 observation times

\begin{tabular}{|l|c|c|c|}
\hline & $\begin{array}{c}\text { Baseline- } \\
\text { 6 months }\end{array}$ & $\begin{array}{c}\text { Base line- } \\
\text { 12 months }\end{array}$ & $\begin{array}{c}\text { 6 months } \\
\text {-12 months }\end{array}$ \\
\hline \multicolumn{4}{|c|}{ Plaque (PI) } \\
\hline Locator group & 1.0 & $.025^{*}$ & $.038^{*}$ \\
\hline SFI bar group & $.023^{*}$ & $.024^{*}$ & $.012^{*}$ \\
\hline \multicolumn{5}{|c|}{ Gingiva (GI) } \\
\hline Locator group & .25 & .41 & .41 \\
\hline SFI bar group & .31 & .30 & .20 \\
\hline \multicolumn{5}{|c|}{ Probing (PD) } \\
\hline Locator group & .25 & $.039^{*}$ & $.023^{*}$ \\
\hline SFI bar group & $.010^{*}$ & $.019^{*}$ & $.024^{*}$ \\
\hline \multicolumn{5}{|c|}{ Stability (IS) } \\
\hline Locator group & .053 & .11 & .087 \\
\hline SFI bar group & .067 & .13 & .10 \\
\hline \multicolumn{5}{|c|}{ Bone loss (BL) } \\
\hline Locator group & - & - & $.012^{*}$ \\
\hline SFI bar group & - & - & \\
\hline
\end{tabular}

\section{DISCUSSION}

Plaque showed significant increase in both groups with passage of time. This may be due to old patients included in the study have a reduced interest for performing adequate cleaning of the attachments despite instructions of performing adequate oral hygiene. The reduced socioeconomical level of the participants together with reduced manual dexterity of the old participants may be another reason of increased plaque accumulation around the attachments with passage of time ${ }^{29,30}$. Despite the fact that SFI bar has a smooth surface as it is being prefabricated as locator attachments, SFI bar group showed significant higher plaque scores than Locator group after 6 and 12 months. The increased plaque scores with SFI bar may be due to patients with bar attachments usually face difficulties in cleaning the gingiva under and around the bar with difficulty in performing appropriate oral hygiene ${ }^{31}$. The increase plaque accumulation around the SFI bar maybe also related to relieve spaces around the bar and the abutments made to permit rotation of overdentures around the bar without implant loading, but help plaque to accumulate ${ }^{32}$. On the other hand, locator attachments are easy to clean due to the un-splinted nature and the smooth surface of the attachments which might be an advantage for elderly patients. Similarly, Kappel et al ${ }^{33}$ found that bars for immediately loaded inter-foraminal implants by overdentures showed increased plaque index than locators. The increase in plaque accumulation was not associated with increased gingival scores. This was in agreement with the observation of another author ${ }^{34}$ who found low gingival scores at all evaluation points for bar and locator attachment groups used to assist maxillary overdentures. They added that gingival index did not significantly differ between groups.

Probing depth showed significant increase in both groups with passage of time. A similar observation was noted in other investigations ${ }^{22,35}$ This may reflect the increased marginal bone loss combined with gingival overgrowth that occurred with time in both groups as confirmed by the results of bone loss in this study. In contrast, Kapur, et al. ${ }^{36}$ showed no significant change in pocket depth with passage of time around implants supporting mandibular overdentures with plastic clip retainers for Hader bar attachments. SFI bar group showed significant higher pocket depth than Locator group after 6 and 12 months. Similarly, Cordaro, et al ${ }^{37}$ reported that the mean peri-implant probing depth values were significantly higher in the $\mathrm{CAD} /$ CAM bar group than locator attachment group for 4-implant supported mandibular overdentures. This may be attributed to the gingival hyperplasia around the bar abutments of SFI bar overdentures ${ }^{34}$. 
The gingival hyperplasia occurred in the bar group may be due to denture spaces that allow denture rotation without implant torquing as stated previously ${ }^{29}$.

There was no significant difference in implant stability between time intervals and or between groups at each time interval. In agreement with this finding, Naert, et al. ${ }^{38}$ found no significant difference in implant stability between splinted and free-standing implants retaining mandibular overdentures. The lack of difference in implant stability between attachments may be due to high basal bone density in the interforaminal area of the mandible ${ }^{29}$. This high density and good bone quality are responsible for increased bone to implant contact, insertion torques and increased implant stability.

Bone loss increased with significant difference from six months to 12 months for both groups. The bone loss could be attributed to maturation of bone after fixture installation and adaptation of bone to resist occlusal loads ${ }^{39}$. Similarly, Elsyad et al. ${ }^{22,35}$ found increased vertical bone loss after one year compared to values at 6 months for immediate loaded 2 implants retaining mandibular overdentures with locator and magnetic attachments. Locator group showed significant higher BL than bar group after 6 and 12 months. This could be attributed to the effective splinting of the implants and greater surface area provided by bar attachment. Also load sharing between implants by bars is very effective in prevention of implant micromotion in case of immediate loading ${ }^{40}$. The stress-free nature of the bar reduces the load transmission resulting from lack of passive fit of the bar. The stress-free nature of the SFI bar ensure complete screwing of the bar without transmitting micromovements the implant to the implants. This is a crucial factor especially in the initial healing period after immediate loading. According to manufacturer, due to the telescopic design of the bar joints, no lateral stress is applied to the implants ${ }^{18}$. The resilient clips transmit the load indirectly to the implants through bar segments. In contrast, the unsplinted nature of the locator attachment may subject the implants to higher forces that may interference with early healing of immediately loaded implants 41, 42. Another explanation could be attributed to implant parallelism. Perfect parallelism between implants is difficult to achieve mesiodistally ${ }^{43}, 44$ or buccolingually ${ }^{12,45}$ due to the presence buccal or lingual undercuts. This caused increased peri-implant stresses around locator attachments which may be associated with increased bone loss ${ }^{12,43-45}$. The implant angulation is not a problem with SFI bar attachments since the ball and socket nature of the attachment adapter permit up to 15 degree implant angulation. Moreover, the overdentures are inserted and removed from clips. However, with resilient stud attachments, the external and internal flanges of the nylon components behave like guiding planes which restrict lateral movement of the prosthesis and may transmit moment loads to the implants during denture insertion and removal ${ }^{45-47}$. The reduced vertical bone loss with bar attachments is in agreement with the findings of Elsyad and Kairallah ${ }^{5}$ who studied the loss of bone around bar and ball anchors with immediately loaded 2-implants using CBCT. The author found that bone loss was higher with unsplinted (ball) retained overdentures than bar retained ones after one-year follow-up.

\section{CONCLUSION}

Within limitation of this study, it is concluded that both Locators and SFI bar anchors are recommended for immediately loaded 2 inter-foraminal implants by mandibular overdentures. However, Locators may be favorable regarding improved peri-implant soft tissue conditions and SFI bar may be favorable regarding reduced marginal bone loss around the implants. 


\section{REFERENCES}

1. Bernhart G, Koob A, Schmitter M, Gabbert O, Stober T, Rammelsberg P. Clinical success of implant-supported and tooth-implant-supported double crown-retained dentures. Clin Oral Investig. 2012;16:1031-7.

2. Alsabeeha NH, Payne AG, De Silva RK, Thomson WM. Mandibular single-implant overdentures: preliminary results of a randomised-control trial on early loading with different implant diameters and attachment systems. Clin Oral Implants Res. 2011;22:330-7.

3. Campelo LD, Camara JR. Flapless implant surgery: a 10year clinical retrospective analysis. Int J Oral Maxillofac Implants. 2002; 17:271-6.

4. Ahn MR, An KM, Choi JH, Sohn DS. Immediate loading with mini dental implants in the fully edentulous mandible. Implant Dent. 2004;13:367-72.

5. Elsyad MA, Khirallah AS. Circumferential bone loss around splinted and nonsplinted immediately loaded implants retaining mandibular overdentures: A randomized controlled clinical trial using cone beam computed tomography. J Prosthet Dent. 2016;116 741-8

6. Turkyilmaz I, Sennerby L, Tumer C, Yenigul M, Avci M. Stability and marginal bone level measurements of unsplinted implants used for mandibular overdentures: a 1-year randomized prospective clinical study comparing early and conventional loading protocols. Clin Oral Implants Res. 2006;17:501-5.

7. Akca K, Akkocaoglu M, Comert A, Tekdemir I, Cehreli MC. Bone strains around immediately loaded implants supporting mandibular overdentures in human cadavers. Int J Oral Maxillofac Implants. 2007;22:101-9.

8. Kleis WK, Kammerer PW, Hartmann S, Al-Nawas B, Wagner W. A comparison of three different attachment systems for mandibular two-implant overdentures: oneyear report. Clin Implant Dent Relat Res. 2010;12:209-18.

9. Trakas T, Michalakis K, Kang K, Hirayama H. Attachment systems for implant retained overdentures: a literature review. Implant Dent. 2006;15:24-34.

10. ELsyad MA, Emera RM, Ashmawy TM. Effect of Distal Implant Inclination on Dislodging Forces of Different Locator Attachments Used for Mandibular Overdentures: An In Vitro Study. J Prosthodont. 2019;28:e666-e74.

11. ELsyad MA, Emera RM, Ibrahim AM. Effect of Labial Implant Inclination on the Retention and Stability of
Different Resilient Stud Attachments for Mandibular Implant Overdentures: An In vitro Study. Int J Oral Maxillofac Implants. 2019;34:381-9.

12. Alameldeen HE, Elsyad MA, Shawky AF, Khirallah AS. The Influence of Implant Inclination on Retention and Periimplant Stresses of Stud-Retained Implant Overdentures During Axial and Nonaxial Dislodgments: An In Vitro Study. Int J Oral Maxillofac Implants. 2020;35:543-50.

13. ELsyad MA, Errabti HM, Mustafa AZ. Mandibular Denture Base Deformation with Locator and Ball Attachments of Implant-Retained Overdentures. J Prosthodont. 2016;25:656-64.

14. Alsiyabi AS, Felton DA, Cooper LF. The Role of Abutment-Attachment Selection in Resolving Inadequate Interarch Distance: A Clinical Report. J Prosthodontics. 2005;14:184-90.

15. ELsyad MA, Fathe Mahanna F, Samir Khirallah A, Ali Habib A. Clinical denture base deformation with different attachments used to stabilize implant overdentures: A crossover study. Clin Oral Implants Res. 2019.

16. Kim HY, Kim RJ, Qadeer S, Jeong CM, Shin SW, Huh JB. Immediate loading on mandibular edentulous patient with SFI Bar(R) overdenture. The journal of advanced prosthodontics. 2011;3:47-50.

17. Wei L, Ma Q, Qin X, Pan S. In Vitro Cyclic Dislodging Test on Retentive Force of Two Types of Female Parts of SFI-Bar. The International journal of prosthodontics. 2016;29:293-5.

18. Ha SR, Kim SH, Song SI, Hong ST, Kim GY. Implantsupported overdenture with prefabricated bar attachment system in mandibular edentulous patient. The journal of advanced prosthodontics. 2012;4:254-8.

19. Kobayashi M, Srinivasan M, Ammann P, Perriard J, Ohkubo $\mathrm{C}$, Muller F et al. Effects of in vitro cyclic dislodging on retentive force and removal torque of three overdenture attachment systems. Clin Oral Implants Res. 2014;25:426-34.

20. Albrecht D, Ramierez A, Kremer U, Katsoulis J, MericskeStern R, Enkling N. Space requirement of a prefabricated bar on two interforaminal implants: a prospective clinical study. Clin Oral Implants Res. 2015;26:143-8.

21. Zarb G,Bolender C, Eckert S, Jacob R, Fenton A, MericskeStern R. Prosthodontic treatment for edentulous patients: complete dentures and implant-supported prostheses. $12^{\text {th }}$ ed St Louis: Mosby. 2003:p. 211-425. 
22. Elsyad MA, Mahanna FF, Elshahat MA, Elshoukouki AH. Locators versus magnetic attachment effect on periimplant tissue health of immediate loaded two implants retaining a mandibular overdenture: a 1-year randomised trial. J Oral Rehabil. 2016;43:297-305.

23. Schincaglia GP, Rubin S, Thacker S, Dhingra A, Trombelli L, Ioannidou E. Marginal Bone Response Around Immediate- and Delayed-Loading Implants Supporting a Locator-Retained Mandibular Overdenture: A Randomized Controlled Study. Int J Oral Maxillofac Implants. 2016;31:448-58.

24. Mombelli A, van Oosten MA, Schurch E, Jr., Land NP. The microbiota associated with successful or failing osseointegrated titanium implants. Oral Microbiol Immunol. 1987;2:145-51

25. Loe H, Silness J. Periodontal Disease in Pregnancy. I. Prevalence and Severity. Acta Odontol Scand. 1963; 21:533-51.

26. Meredith N, Alleyne D, Cawley P. Quantitative determination of the stability of the implant-tissue interface using resonance frequency analysis. Clin Oral Implants Res. 1996;7:261-7.

27. Glauser R, Sennerby L, Meredith N, Ree A, Lundgren A, Gottlow $\mathrm{J}$ et al. Resonance frequency analysis of implants subjected to immediate or early functional occlusal loading. Successful vs. failing implants. Clin Oral Implants Res. 2004; 15:428-34.

28. Canullo L, Fedele GR, Iannello G, Jepsen S. Platform switching and marginal bone-level alterations: the results of a randomized-controlled trial. Clin Oral Implants Res. 2010;21:115-21.

29. ElSyad MA, Denewar BA, Elsaih EA. Clinical and Radiographic Evaluation of Bar, Telescopic, and Locator Attachments for Implant-Stabilized Overdentures in Patients with Mandibular Atrophied Ridges: A Randomized Controlled Clinical Trial. Int J Oral Maxillofac Implants. 2018;33:1103-11.

30. ELsyad MA, Alameldeen HE, Elsaih EA. Four-implantsupported fixed prosthesis and milled bar overdentures for rehabilitation of the edentulous mandible: A 1-year randomized controlled clinical and radiographic study. Int J Oral Maxillofac Implants. 2019;34:1493-503.

31. Behneke A, Behneke N, d'Hoedt B. A 5-year longitudinal study of the clinical effectiveness of ITI solid-screw implants in the treatment of mandibular edentulism. Int $\mathbf{J}$ Oral Maxillofac Implants. 2002;17:799-810.
32. Lachmann S, Kimmerle-Muller E, Gehring K, Axmann D, Gomez-Roman G, Watzek G et al. A comparison of implant-supported, bar- or ball-retained mandibular overdentures: a retrospective clinical, microbiologic, and immunologic study of 10 edentulous patients attending a recall visit. Int J Prosthodont. 2007;20:37-42.

33. Kappel S, Giannakopoulos NN, Eberhard L, Rammelsberg P, Eiffler C. Immediate Loading of Dental Implants in Edentulous Mandibles by Use of Locator(R) Attachments or Dolder(R) Bars: Two-Year Results from a Prospective Randomized Clinical Study. Clin Implant Dent Relat Res. 2016;18:752-61.

34. Zou D, Wu Y, Huang W, Wang F, Wang S, Zhang Z et al. A 3-year prospective clinical study of telescopic crown, bar, and locator attachments for removable four implantsupported maxillary overdentures. Int J Prosthodont. 2013;26:566-73.

35. Elsyad MA, Elsaih EA, Khairallah AS. Marginal bone resorption around immediate and delayed loaded implants supporting a locator-retained mandibular overdenture. A 1-year randomised controlled trial. J Oral Rehabil. 2014;41:608-18.

36. Kapur KK, Garrett NR, Hamada MO, Roumanas ED, Freymiller E, Han $\mathrm{T}$ et al. A randomized clinical trial comparing the efficacy of mandibular implant-supported overdentures and conventional dentures in diabetic patients. Part I: Methodology and clinical outcomes. J Prosthet Dent. 1998;79:555-69.

37. Cordaro L, di Torresanto VM, Petricevic N, Jornet PR, Torsello F. Single unit attachments improve peri-implant soft tissue conditions in mandibular overdentures supported by four implants. Clin Oral Implants Res. 2013;24:536-42.

38. Naert I, Gizani S, Vuylsteke M, van Steenberghe D. A 5-year randomized clinical trial on the influence of splinted and unsplinted oral implants in the mandibular overdenture therapy. Part I: Peri-implant outcome. Clin Oral Implants Res. 1998;9:170-7.

39. Albrektsson T, Zarb G, Worthington P, Eriksson AR. The long-term efficacy of currently used dental implants: a review and proposed criteria of success. Int $\mathrm{J}$ Oral Maxillofac Implants. 1986;1:11-25.

40. Krennmair G, Krainhofner M, Piehslinger E. Implantsupported mandibular overdentures retained with a milled bar: a retrospective study. Int J Oral Maxillofac Implants. 2007;22:987-94 
41. Mericske-Stern R, Piotti M, Sirtes G. 3-D in vivo force measurements on mandibular implants supporting overdentures. A comparative study. Clin Oral Implants Res. 1996;7:387-96.

42. Misch CE, Wang HL, Misch CM, Sharawy M, Lemons J, Judy KW. Rationale for the application of immediate load in implant dentistry: part II. Implant Dent. 2004;13:310-21.

43. Elsyad MA, Setta FA, Khirallah AS. Strains around distally inclined implants retaining mandibular overdentures with Locator attachments: an in vitro study. The journal of advanced prosthodontics. 2016;8:116-24.

44. Elsyad MA, Eltowery SM, Gebreel AA. Peri-implant strain around mesially inclined two-implant-retained mandibu- lar overdentures with Locator attachments. J Oral Sci. 2017;59:483-90.

45. Elsyad MA, Abid KS, Elkhalek EA. Effect of Buccal Implant Inclination on Stresses Around Two-Implant-Retained Overdentures with Resilient Stud Attachments. Int J Oral Maxillofac Implants. 2017;32:e135-e42.

46. Elsyad MA, Eltowery SM, Gebreel AA. Peri-implant strain around mesially inclined two implants retaining mandibular overdentures with Locator attachments. J Oral Sci. 2017.

47. ELsyad MA, Setta FA, Khirallah AS. Strains around distally inclined implants retaining mandibular overdentures with Locator attachments. An in vitro study The journal of advanced prosthodontics. 2016;8 116-24. 